\title{
British Columbia revamps process for determining drug coverage
}

$\mathrm{T}$ he British Columbia Ministry of Health is facing a firestorm about plans to change its process for determining which drugs are to be covered by the province's Pharmacare plan.

The changes will bring BC's drug review process into line with provincial counterparts and likely result in more drugs getting approved and covered, but safety advocates fret the aim is to provide the pharmaceutical industry a more prominent role.

Five expert groups, which haven't yet been named, will conduct future drug reviews. But the University of British Columbia-based group, the Therapeutics Initiative, which had been under contract since 1994 to provide reviews, will have its role in the process significantly diminished, if not entirely curtailed. (It has applied to become a designated expert panel).

The changes come on the heels of an assessment of BC's drug listing process conducted by a provincial task force and an assessment of the Therapeutics Initiative conducted by an academic panel.

The Pharmaceutical Task Force recommended that BC adopt "operational reforms" to bring it into line with the national Common Drug Review, including its approach to interactions with industry and clinicians (www .health.gov.bc.ca/library/publications /year/2008/PharmaceuticalTaskForce Report.pdf).

The academic panel, meanwhile, found that the Therapeutics Initiative had an excellent international reputation but only "modest" academic productivity in terms of peer-reviewed grants and publications, in part because it didn't collaborate with similar bodies. The panel advised UBC to revamp the Initiative's management and leadership.

Opinion about the group was severely divided, says Jean Gray, panel member and professor emeritus at Dalhousie University in Halifax, Nova

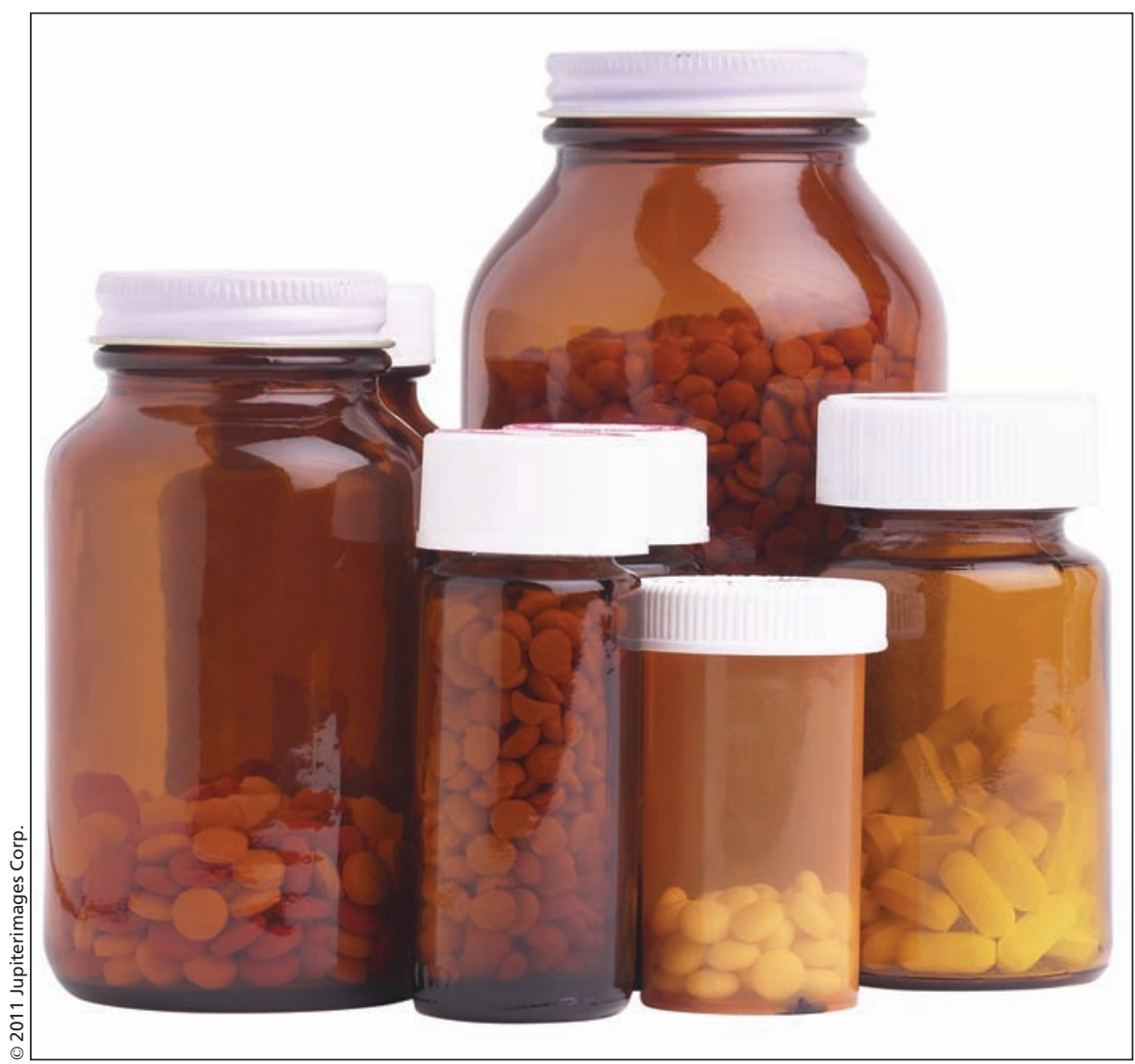

More drugs are expected to be approved and covered under British Columbia's new regime for reviewing drugs. Since 1994, the University of British Columbia-based Therapeutics Initiative had been conducting all drug reviews but the group's role in the process will be diminished, if not curtailed.

Scotia. "It was 180 degrees, there was no middle ground. The first person you'd talk to would be so opposed and the next person you'd talk to would be a rabid fan." Family physicians in BC were supportive, while specialists were generally opposed.

The fact that all $\mathrm{BC}$ drug reviews were being conducted by the Therapeutics Initiative, essentially without input from pharmaceutical firms, specialists or patients gave the province "a reputation of a fairly closed system re: drug reimbursement," writes Anne Holbrook, director of the Division of Clinical Pharmacology in the Department of Medicine at McMaster University in Hamilton, Ontario, in an email. Holbrook adds that the knowledge and judgment of clinicians "is the most useful for the entire drug reimbursement process."

Other provinces and the national Common Drug Review have sought more external advice than $\mathrm{BC}$, making the province "an extreme outlier compared to the rest of the country" in terms of its drug listings, says Dr. Stuart Macleod, UBC professor of pediatrics and vice president (research) at BC's Provincial Health Services Authority. "There are patterns of drug use that show you that BC is different" in part because of policies resulting from Therapeutics Initiative advice.

The province updated its drug reviewing plans within that highly 
polarized environment at a Nov. 24, 2010 meeting, which ministry spokesman Brian Cotton described as a "very positive forum for stakeholder engagement," and Therapeutics Initiative director Jim Wright dubbed it a "show and tell of how everything was going to be favorable to drug companies."

The province's reforms will see reviews overseen by a Drug Benefit Council. A "Drug Review Resource Committee, a sub-committee of the Drug Benefit Council determines individual review requirements, maintains the rosters of expert reviewers and assigns the actual review work," according to a Sept. 30, 2010, memo from John Dyble, the province's deputy health minister, that the ministry provided to CMAJ (available at www .caut.ca/uploads/100930Stakeholders letter.pdf). "In the area of Clinical Practice Review, there are 18 rosters of General Practitioners and specialists that can be called upon for reviews in their areas of expertise. Participation is open to all qualified BC physicians."

The latter change is the product of how clinical specialists felt shut out of the process, says Dr. Brian Warriner, head of UBC's department of anesthesiology, pharmacology and therapeutics.

The government has also indicated that the new process "lets British Columbia patients, caregivers and patient advocacy groups submit input on specific drug reviews" (www.health.gov .bc.ca/pharmacare/outgoing/drugrevproc .pdf). Patients, caregivers and disease advocacy groups can use an online questionnaire to express opinions about a drug (www2.news.gov.bc.ca/news _releases_2009-2013/2010HSERV0072 -001415.htm).

And as with the Common Drug Review, BC will provide opportunities for drug manufacturers to interact at four points in the process (www.health .gov.bc.ca/pharmacare/formulary/drug subsponsor.html).
Where does all that leave the Therapeutics Initiative, which had received $\$ 1$ million annually from the province to conduct reviews?

Waiting, against odds, to hear if it will be selected as one of the favored panels.

Wright is hopeful publicity saves the group but Warriner notes that it didn't do itself any favors by ignoring task force and academic panel demands for management changes.

Wright believes the changes are part of a "global phenomenon" in which the pharmaceutical industry is gaining more clout. He writes in an email that the UK's National Institute for Health and Clinical Evidence lost its authority to guide drug decisions for the National Health Service; "That's similar to us. They've been castrated." - Miriam Shuchman MD, Toronto, Ont.

CMAJ 2011. DOI:10.1503/cmaj.109-3758 